\title{
Reflexões acerca do papel do fonoaudiólogo junto à família de uma criança com Transtorno Global do Desenvolvimento: estudo de caso
}

\author{
Considerations about the role of a speech-language pathologist \\ with the family of a child with Pervasive Development \\ Disorder: case report
}

\author{
Marta Cecília Rabinovitsch Gertel ${ }^{1}$, Suzana Magalhães Maia²
}

\begin{abstract}
RESUMO
O objetivo deste artigo foi refletir e discutir o papel do fonoaudiólogo na condução das estratégias terapêuticas junto à família de uma criança com Transtorno Global do Desenvolvimento. Esta pesquisa foi desenvolvida por meio de estudo de caso de uma criança com Transtorno Global do Desenvolvimento atendida de julho/2002 a novembro/2004. Os recortes do material clínico retratam o percurso seguido ao longo do eixo da história do paciente enfatizando os momentos significativos que geraram desenvolvimento do processo terapêutico fonoaudiológico no que se refere à comunicação oral e integração social no ambiente familiar. O enfoque das estratégias clínicas foi direcionado para propiciar um ambiente físico e emocional capaz de promover experiências constitutivas que respeitem a singularidade de cada paciente levando em conta a realidade da família e da comunidade onde se encontra inserido aquele núcleo social. Portanto, em nosso entender, a atuação fonoaudiológica pode ser direcionada para a criação de situações que favoreçam o processo [de cada paciente] de inclusão na vida cotidiana, com o respeito que todas as pessoas merecem.
\end{abstract}

Descritores: Transtornos globais de desenvolvimento infantil; Estudos de Casos; Fonoterapia; Condutas terapêuticas; Família; Relações familiares

\section{INTRODUÇÃO}

No campo fonoaudiológico, uma questão que vem sendo discutida diz respeito à forma como nossa intervenção clínica pode favorecer a inserção do indivíduo em sua família e na sociedade, o que adquire fundamental relevância em se tratando de pacientes com necessidades especiais ${ }^{(1)}$.

A categoria distúrbios de comportamento ${ }^{(1)}$ engloba diversos quadros, entre eles os classificados como Autismo, Transtorno Invasivo do Desenvolvimento (TID) e Transtorno Global

Trabalho realizado na Pontifícia Universidade Católica de São Paulo - PUC-SP - São Paulo (SP), Brasil, como parte de dissertação apresentada à instituição para obtenção do título de Mestre em Fonoaudiologia, com bolsa concedida pela Coordenação de Aperfeiçoamento de Pessoal de Nível Superior - CAPES. (1) Pós-Graduanda (Doutorado) em Fonoaudiologia pela Pontifícia Universidade Católica de São Paulo - PUC-SP - São Paulo (SP), Brasil.

(2) Doutora, Professora da Faculdade e do Programa de Estudos PósGraduados em Fonoaudiologia da Pontifícia Universidade Católica de São Paulo - PUC-SP - São Paulo (SP), Brasil.

Endereço para correspondência: Marta Cecília Rabinovitsch Gertel. Av. Angélica, 672/91, Higienópolis, São Paulo (SP), Brasil, CEP: 01228-000.

Email: martagertel@uol.com.br

Recebido em: 2/7/2009; Aceito em: 4/4/2010 do Desenvolvimento (TGD). Nesses casos o desenvolvimento se encontra acentuadamente alterado em três áreas principais: interação social, comunicação e repertório restrito de atividades e interesses. As manifestações clínicas nestas áreas devem ser observadas antes do terceiro ano de vida e o quadro não envolve, necessariamente, todas as áreas do comportamento na mesma proporção.

Pesquisas assinalam a prevalência do quadro em meninos, mas ainda não existe um consenso quanto a um possível determinante orgânico (genético e/ou hereditário). Quanto aos dados relativos à sua incidência na população, estes podem ser considerados, muitas vezes, discrepantes devido ao uso de critérios diagnósticos diversos ${ }^{(2-4)}$.

Um aspecto que merece destaque é a dificuldade encontrada por profissionais da área da saúde no que se refere ao diagnóstico precoce deste quadro, mesmo quando há queixa por parte dos pais quanto ao desenvolvimento do filho. A variedade no grau de severidade desse transtorno e a importância da capacitação dos profissionais da área da saúde para acolherem com maior relevância as informações e preocupações trazidas pela família seriam alguns dos principais motivos para o não diagnóstico antes do terceiro ano de vida ${ }^{(2-5)}$. 
A literatura fonoaudiológica nacional é relativamente vasta e ressalta a importância do diagnóstico e intervenção precoce nesses casos. É possível encontrar diversas fundamentações teóricas que pautam as abordagens terapêuticas com crianças com distúrbios do comportamento ${ }^{(1)}$, entretanto, os objetivos finais são os mesmos: melhorar as habilidades linguísticas, sociais e cognitivas desses pacientes visando a inserção social, escolar e familiar da criança ${ }^{(4-6)}$.

Cabe ressaltar aqui que trabalhos que tratam da relação entre linguagem e socialização em crianças com distúrbios do comportamento ${ }^{(1)}$ não são frequentes na literatura fonoaudiológica, apesar de ambos (linguagem e socialização) serem mutuamente interferentes e se desenvolverem em paralelo. Da mesma maneira é fato que a intervenção precoce favorece o desenvolvimento destas áreas interdependentes e fundamentais para a inserção social ${ }^{(6,7)}$.

Também já é possível encontrar na literatura fonoaudiológica vários artigos, livros e pesquisas que apontam para um crescente interesse da área nos aspectos subjetivos envolvidos na comunicação. Neste sentido, os subsídios da Psicanálise auxiliam a reconhecer a demanda subjacente à queixa de cada paciente de modo a orientar a condução do processo terapêutico fonoaudiológico desde as entrevistas preliminares ${ }^{(8,9)}$.

Nossa abordagem clínica e de pesquisa encontra-se incluída nesta linha teórica e tem procurado seguir preceitos básicos que buscam desvendar maneiras de acolher o paciente, a queixa e a demanda envolvida, compreendendo, assim, por meio da relação terapêutica, necessidades e questionamentos que atravessam a vida da pessoa que chega para atendimento ${ }^{(10,11)}$.

Ao contemplar essa perspectiva clínica procura-se desvendar as necessidades fundamentais de cada pessoa, criança ou adulto, na busca de se constituir como si mesmo. Nesse processo, o ambiente humano é de suma importância, ou seja, o outro na constituição de uma pessoa favorecendo o acontecer humano e o início desse processo ocorre a partir da primeira relação que o bebê estabelece com outro ser humano: sua mãe*(12,13).

Assim, o processo de constituir-se não é finito e é fundamentado por meio das relações sociais que cada pessoa estabelece ao longo de sua vida. Nesta direção, a base do trabalho terapêutico deve ser concebida de modo que o terapeuta direcione sua prática clínica tendo em vista as condições necessárias para favorecer o acontecer humano daquele que chega em busca de atendimento.

Procuramos destacar aqui a importância do terapeuta considerar as características de cada família - fruto de sua história e retrato de sua herança cultural - e de como as mesmas podem influir na condução das estratégias terapêuticas fonoaudiológicas. É necessário assinalar que, no caso dos fonoaudiólogos, embora muitos privilegiem a inclusão da família no processo terapêutico, não existe um consenso quanto à como fazê-lo ${ }^{(11-14)}$.

De modo geral encontramos trabalhos e pesquisas que priorizam o uso de dados e/ou informações fornecidas pela família na anamnese, entrevista ou em contatos periódicos, de modo a avaliar o desenvolvimento ou possíveis falhas no processo terapêutico principalmente no que se refere às habilidades sócio-comunicativas de crianças com distúrbios do comportamento $^{(1-4,6,7)}$.

Direcionar o atendimento à família de modo a respeitar a singularidade desse ambiente fundamental na constituição de cada pessoa não implica que o fonoaudiólogo deva interpretar os conteúdos apresentados ${ }^{(9)}$. O respeito às características familiares e do paciente favorece a aplicação dos procedimentos técnicos fonoaudiológicos de acordo com suas necessidades [da família e do paciente] e o espaço terapêutico coloca-se como facilitador de desenvolvimento e de evolução ${ }^{(10,11)}$.

Tendo em vista as considerações realizadas até aqui, nosso objetivo é apresentar o relato de um estudo de caso de uma criança com diagnóstico médico de Transtorno Global do Desenvolvimento (TGD), onde a ênfase será dada aos aspectos envolvidos nos atendimentos à família.

\section{APRESENTAÇÃO DO CASO CLÍNICO}

O presente estudo foi aprovado pela Comissão de Ética e Pesquisa da Pontifícia Universidade Católica de São Paulo (PUC-SP) com o número 018/2007 e a mãe assinou o Termo de Consentimento Informado.

A criança, aqui denominada M., foi atendida pela fonoaudióloga-pesquisadora de julho de 2002 a novembro de 2004 . O material utilizado na composição dos dados referentes a esta pesquisa foi elaborado pela pesquisadora ao longo do processo terapêutico a partir de registros em forma de relatórios e abrangem o material clínico obtido nos atendimentos à família.

Os recortes no material obtido procuraram retratar o percurso seguido ao longo do eixo da história do paciente e os momentos significativos que geraram desdobramentos no desenvolvimento do processo terapêutico fonoaudiológico no que se refere à comunicação oral e integração social no ambiente familiar.

Os aspectos específicos envolvidos nas sessões de atendimento da criança não são descritos ou analisados, pois fugiriam ao objetivo deste artigo. Entretanto, são mencionados ao longo do relato deste caso dados gerais do processo terapêutico, desde que façam parte e sejam pertinentes para circunscrever os atendimentos à família e a evolução clínica do paciente.

\section{O caso $M$.}

M. foi encaminhado para uma avaliação fonoaudiológica em julho/2002 pela escola com queixa de falar pouco. Nossos primeiros encontros foram marcantes: M. chegava aos berros e pontapés, não passava da sala de espera e a mãe (R.) parada na soleira, pedia desculpas sem parar, enquanto eu tentava conseguir, pelo menos, um olhar de atenção dele.

Durante o mês de julho/2002, ao longo de vários encontros, R. foi relatando a história do filho. Aos três anos, gênero masculino, era o segundo filho de uma prole de três (irmã com cinco anos e irmão com dois anos), ambos os pais com

\footnotetext{
* Cabe ressaltar que a mãe representa a pessoa que exerce a função de maternagem, ou seja, na ausência da mãe biológica este papel pode ser assumido por outra pessoa que desempenhará essa função como, por exemplo, o pai, a avó, a babá entre outros.
} 
37 anos. M. frequentava a escola desde os dois anos e oito meses (fevereiro/2002) e, de fato, a queixa principal era de que ele falava muito pouco como referiam a professora e coordenadora. Contou também que a família pertencia à religião judaica, eram ultra-ortodoxos e que, por conta disso, desde que M. nascera, R. falava com ele em idish**. Há mais ou menos um ano, como M. não falava nada, começou a comunicar-se com ele em português.

R. referia que a gestação tinha transcorrido sem intercorrências e o parto a termo, do tipo cesárea, por apresentar dilatação pélvica insuficiente. Ainda de acordo com a mãe, o filho sempre foi uma criança tranquila, tinha sido amamentado até um ano e o pediatra observava discreto atraso no desenvolvimento neuro-psico-motor, pois com um ano e quatro meses não apresentava marcha independente. Nesta idade, em um acidente doméstico, M. sofreu uma queimadura séria no braço esquerdo (das costas até o cotovelo); permaneceu internado durante uma semana e foi submetido à cirurgia para enxerto de pele.

Durante os seis meses seguintes, por ordem médica, M. não podia brincar no chão, se sujar, molhar ou esbarrar em algo que o machucasse tendo em vista o risco de infecção e rejeição ao enxerto de pele. Ainda de acordo com a mãe, após o episódio da queimadura, M. se tornou muito agitado e não entendia o não, tinha dificuldade para aceitar mudanças em sua rotina diária e, quando contrariado, ficava muito irritado, com sérias crises de birra.

M. havia entrado na escola*** em fevereiro/2002, mas a família não observara grandes evoluções no comportamento e na comunicação do filho. Já havia realizado um PEATE (solicitado por um otorrinolaringologista quando apresentou um quadro de otite aguda) com resultado dentro dos parâmetros da normalidade. Quanto à socialização M. não brincava com outras crianças, incluindo os irmãos e os primos.

Para a mãe o comportamento de M. era considerado o jeito dele e que com o amadurecimento iria melhorar. Também referia que por serem muito religiosos tinham que aceitar a vontade de Deus. Não havia nenhum comentário ou queixa quanto ao fato de M. não manter contato visual, não esboçar qualquer atitude comunicativa ou interesse pelo outro ou pelo ambiente físico. Tudo era creditado ao jeito dele.

À avaliação fonoaudiológica, realizada durante o mês de julho/2002, M. mostrou-se uma criança extremamente difícil: não mantinha contato visual e não demonstrou interesse por nenhuma das atividades propostas e/ou brinquedos apresentados nas diversas sessões a que compareceu. Quando aceitava algum brinquedo, por exemplo, um carrinho ou bola, levavaos constantemente à boca ou batia o mesmo no chão com movimentos repetitivos. Também foi observada a presença de comportamentos atípicos sistemáticos como bater o receptor do telefone na mesa, tocar a campainha, permanecer com o olhar fixo nas mãos enquanto executava movimentos rotatórios com os dedos e/ou punhos, deitar-se ao chão e permanecer passando a língua neste.
M. apresentava dificuldade severa para compreender ordens simples, mesmo quando acompanhadas de gestos indicativos e/ou representativos, bem como o respeito de limites impostos pela mãe e/ou pela terapeuta como quando solicitávamos que ele parasse de bater o telefone ou lamber o chão.

No que se refere à comunicação não verbal não foi observada a presença e/ou uso de gestos indicativos e representativos; quando M. queria algo, por exemplo, um copo de água, pegava a mão da mãe ou da terapeuta e levava até a jarra de água. Outro fato que chamava atenção era a expressão facial de M: raramente se alterava independente de sua atitude.

Quanto à comunicação oral, M. apresentava vocalizações esporádicas, aparentemente sem relação com o contexto, e gritos quando contrariado. Também apresentava, com menor frequência, repetições de frases aleatórias que, de acordo com a mãe, pertenciam a desenhos infantis que ele assistia em casa.

Tendo em vista o relato da mãe e os dados obtidos na avaliação fonoaudiológica a proposta terapêutica de M. foi direcionada para a estimulação global e desenvolvimento das habilidades comunicativas e sociais. Também foi sugerido o encaminhamento para avaliação neurológica, mas R. solicitou que contatássemos o pediatra da criança, profissional de sua confiança como relatou. Foi feito contato com o pediatra e a escola de $\mathrm{M}$.

No que se refere ao pediatra de M. este referia discreto atraso no desenvolvimento global de M., mas tendo em vista o histórico da grave queimadura de M. não observava necessidade de encaminhá-lo para avaliação neurológica como sugerido pela fonoaudióloga-pesquisadora. Os pais acataram a decisão do pediatra.

Quanto à escola foi feito contato e reuniões sistemáticas com a coordenadora e as professoras de M. ao longo de todo o tratamento de M. (julho/2002 a novembro/2004). Os dados destes encontros não serão relatados aqui, pois fogem à proposta deste artigo.

Iniciamos o atendimento de M. com sessões diárias de aproximadamente 30 minutos e com a presença da mãe em sala, pois M. recusava-se a entrar sem ela: jogava-se ao chão, batia a cabeça na parede, mordia e chutava a mãe e a terapeuta. Os encontros com a mãe eram realizados de acordo com a necessidade observada pela terapeuta. Em geral, ocorriam três vezes por semana antes da sessão de M. quando ele chegava dormindo ou em horários separados.

Nestes encontros nossa proposta era refletir em conjunto com a mãe acerca da visão da família quanto ao comportamento de M. ser creditado ao jeito dele e acolher as questões, muitas vezes precariamente formuladas, que R. trazia. Entre os assuntos abordados podemos citar alguns temas recorrentes: meu filho vai ser normal; quando isso (os comportamentos de M.) vai terminar; a vergonha em relação aos comportamentos do filho em ambientes que a família frequentava como a casa de parentes, a sinagoga, a escola; o evitar sair para passear por conta dos comportamentos de M.; é só falta de limite mesmo?

\footnotetext{
** Idish é um dialeto utilizado por judeus de origem européia bastante difundido entre a população judaica até a II Guerra Mundial. Atualmente, esse dialeto só é utilizado por comunidades ultra-ortodoxas que não falam o hebraico.

*** A escola frequentada por M. pertence à comunidade judaica e também segue a linha ultra-ortodoxa.
} 
Em dezembro de 2002, recebi pai e mãe, pois até então, meu contato era exclusivamente com a mãe. Ambos ressaltaram que $M$. estava menos agitado e já aceitava a aproximação de outras crianças, incluindo o irmão mais novo: não brincavam, mas ele já não o agredia. Também referiam que $\mathrm{M}$. continuava repetindo frases aleatórias que acreditavam estar relacionadas aos desenhos que assistia regularmente, mas aparentemente, sem relação com algum contexto específico ou solicitando algo.

Neste encontro, o que mais chamou minha atenção foi que só a mãe falava, enquanto o pai não olhava para mim e ficava o tempo todo folheando um livro de rezas. Quando perguntado diretamente sobre o que estava achando do atendimento fonoaudiológico, disse que não conseguia se fazer entender para M. e também não conseguia entendê-lo. Ao ser perguntado sobre como agia quando estava sozinho com M.: "Não fico sozinho, se não entendo, peço para R. traduzir”. É possível compreender aqui a difícil posição que a mãe precisava assumir: como intérprete oficial de M. e, ao mesmo tempo, como aquela que, aos poucos, precisava favorecer seu processo de independência com o mundo que o rodeava.

No que se refere ao atendimento fonoaudiológico ao final do segundo semestre/2002, M. já entrava sozinho nas sessões apesar, de algumas vezes solicitar a presença da mãe: nestas ocasiões pegava a mão da mãe e levava-a até a porta da sala de atendimento. $\mathrm{O}$ contato visual era frequente, demonstrava interesse por algumas atividades lúdicas como jogar bola, brincar de roda e saltar. Ainda apresentava comportamentos atípicos como girar as mãos ou pequenos objetos e nítida dificuldade para compreensão de ordens simples quando não acompanhadas de gestos.

Quanto à comunicação oral ainda apresentava os mesmos comportamentos descritos na avaliação fonoaudiológica com discreta melhora na aceitação de limites impostos pela terapeuta como, por exemplo, para não colocar a boca no chão. Para o primeiro semestre de 2003 nossa proposta terapêutica permanecia semelhante a 2002: sessões fonoaudiológicas diárias e a continuidade dos encontros com a mãe. $\mathrm{O}$ foco principal era o contato visual e o desenvolvimento das habilidades comunicativas e sociais de $\mathrm{M}$. em casa e na escola.

Durante o primeiro semestre de 2003 já observávamos que M. mantinha contato visual frequente e por um tempo mais longo, mas continuava não atender quando chamado pelo nome. M. passou a repetir, assistematicamente, o final de frases emitidas pela terapeuta e aumentou a incidência de repetição de frases dos desenhos que assistia em casa. Ainda não era possível relacionar com um contexto específico para o aparecimento ou o uso dessas frases, entretanto suas emissões eram nítidas, as palavras bem articuladas, sem trocas fonêmicas, com intensidade de voz mais forte e sempre olhando para o interlocutor: a mãe ou a terapeuta.

Nos atendimentos à mãe havia referência à melhora no comportamento de M., principalmente quanto às alterações em sua rotina diária: mudança de caminho para ir à escola e para visitar os avós. A realização de passeios, visitas a outros familiares e ida a sinagoga ainda era pouco frequente por receio do comportamento de M. nestes locais. Entretanto já era possível observar um primeiro movimento de exploração ao meio, do mundo para além da casa: a busca por viver novas experiências, conviver com outras pessoas.

No final de julho/2003, em encontro com o pai e a mãe, observamos o mesmo comportamento por parte de ambos: o pai não falava nada e quando questionado sobre o desenvolvimento de sua relação com M. continuava afirmando a necessidade da intervenção de R. como tradutora dos comportamentos e vontades do filho. Quanto à mãe referia os aspectos que observava no desenvolvimento de M. como mencionado acima. A proposta para atendimento de M. e sua mãe no segundo semestre de 2003 seguia nos mesmos moldes do semestre anterior.

Durante o segundo semestre de 2003 M. apresentou significativo avanço em suas habilidades comunicativas e sociais: uso sistemático de vocábulos-chave/sentenças-chave para a comunicação oral (não, dá, qué, qué água; não qué bola; qué passia; qué xixi). Geralmente essas emissões eram acompanhadas por gestos indicativos (apontando o objeto solicitado) e/ou representativos (balançar a cabeça para o não) e por contato visual com o interlocutor (terapeuta/mãe). A repetição das frases dos desenhos que assistia, bem como do final das frases da terapeuta e da mãe tiveram sua incidência diminuída consideravelmente.

No que se refere à comunicação não verbal M. apresentava contato visual com o interlocutor consolidado, bem como a exploração do meio através da visão e da manipulação dos objetos ou da exploração do espaço físico. Também passou a apresentar expressões faciais e corporais que indicavam alegria, tristeza, risada, choro com lágrimas com maior frequência traduzindo claramente seu estado de espírito.

Quanto à compreensão observamos maior facilidade para M. atender ordens simples, principalmente quando acompanhadas de gestos representativos e/ou indicativos, ou do uso de vocábulos-chave: pega a bola, dá para a terapeuta, joga para a mamãe, está na hora de guardar. M. passou a explorar de maneira lúdica brinquedos e/ou objetos diferentes como instrumentos musicais, bola, massinha, lápis de cor, entre outros.

Em novembro/2003 na reunião com os pais, a mãe relatou que o filho já apresentava atitudes comunicativas espontâneas em casa como pedir água, comida, ir para a escola. Também se mostrava mais interessado em atividades lúdicas além do vídeo, como quebra-cabeça e carrinhos. O pai ainda referia pouco contato com M., pois não conseguia se organizar para passar mais tempo sozinho com o filho. Em contrapartida, M. estava brigando muito com os irmãos, pois não conseguia aceitar quando eles queriam o mesmo brinquedo ou quando não queriam dar-lhe algo. $\mathrm{O}$ fato que merece destaque nesta época era que M. não era mais considerado o estranho, que só queria as coisas do jeito dele. O jeito dele, agora, fazia parte da família.

Nossa proposta terapêutica para 2004 era reduzir o atendimento de M. para três vezes na semana e manter os atendimentos à mãe de acordo com sua necessidade. Em geral esses encontros ocorriam uma ou duas vezes por semana. A ênfase nestes atendimentos visava a reflexão acerca da mudança do papel da mãe como tradutora exclusiva dos comportamentos de M. para o pai e outros familiares, além de incentivar a realização de passeios, visitas aos familiares e ida à sinagoga, importante local de socialização para a comunidade ultra- 
ortodoxa judaica. Também solicitamos a avaliação neurológica de M. o que foi aceito pelos pais****.

Durante o ano de 2004 observamos nítido avanço no uso efetivo da comunicação oral por parte de M.: já atendia ordens simples e também fazia uso de emissões do tipo: quer xixi banheiro; quer tambor; cadê Nala (boneco do desenho Teletubbies), M. vai escola?. M. também apresentou redução acentuada das repetições de frases de desenhos, da terapeuta e da mãe. $\mathrm{O}$ uso de gestos indicativos e/ou representativos ocorriam em poucas situações apontando, claramente, a preferência de M. pela comunicação oral.

Observamos maior facilidade para compreensão de ordens simples e de média complexidade, sem a necessidade do uso de gestos representativos e/ou indicativos: vamos desenhar com caneta ou lápis de cor? Vamos jogar a bola grande ou a pequena? Você quer quebra-cabeça ou memória?. Além disso, o brincar de M. refletia uma interação mais lúdica, principalmente em situações que já conhecia por meio dos desenhos que assistia, de histórias ou da própria vivência, por exemplo, ao usar miniaturas para montar uma cidade, uma estação de trem, uma fazenda. No que se refere à socialização de M. o respeito aos limites colocados pela mãe e/ou pela terapeuta já eram obedecidos de forma mais tranquila.

Em dezembro/2004 na reunião com os pais a mãe já referia que M. já aceitava mais contato físico como abraços e beijos; também já aceitava a vez do outro no jogo, brincava melhor com os irmãos, inclusive respeitando quando estes não queriam lhe dar algum brinquedo que desejava. A ida à escola, à casa de familiares ou a sinagoga estava mais tranquila. Ainda de acordo com a mãe M. já respondia oralmente quando outras pessoas conversavam com ele e não apresentava mais comportamentos agressivos quando contrariado. O pai referia estar conseguindo entender o que M. queria e já saía com ele sozinho esporadicamente para passear aos domingos.

Era nítido o avanço que podia ser observado no desenvolvimento de $\mathrm{M}$. em sua relação com o mundo (ambiente humano) tanto no que se refere à sua comunicação como sua interação social. Da mesma maneira os atendimentos à mãe foram decisivos para o desenvolvimento de $\mathrm{M}$. em sua relação com a família.

\section{DISCUSSÃO}

Um aspecto relevante no caso apresentado reflete a tendência dos profissionais (pediatra, professora e coordenadora) que tinham contato com M. a minimizar seus comportamentos e a queixa apresentada pela mãe. Creditar esses comportamentos ao jeito dele, a queimadura grave ou ao fato da mãe se comunicar com ele em uma segunda língua reforça o que é descrito na literatura quanto à dificuldade para o diagnóstico precoce em crianças com distúrbio do comportamento ${ }^{(1,2,5)}$.

Neste sentido, é importante retomar a importância do papel que o fonoaudiólogo exerce no atendimento de pacientes com comprometimento ou alterações severas de comunicação, como é o caso das crianças com Transtorno Global do Desenvolvimento. Muitas vezes, o fonoaudiólogo é um dos primeiros profissionais para quem a família se dirige - o que ocorreu com M. Neste sentido, seu papel é fundamental, tanto no processo diagnóstico como no processo terapêutico para o desenvolvimento da comunicação e da interação social ${ }^{(7-11)}$.

A partir da vivência clínica é possível considerar que esse lugar de importância do fonoaudiólogo se dá, principalmente, por dois fatores: primeiro porque as dificuldades envolvidas na comunicação pais-filho encontram-se nitidamente presentes (queixa primeira dos pais), e em segundo lugar porque, na maioria das vezes, após receber o diagnóstico, os pais se sentem literalmente perdidos no jargão médico ${ }^{(11)}$.

Também é necessário destacar a importância de compreender cada paciente a partir dos elementos originários que o constituem: a família, suas tradições, as questões que a atravessam ao longo das gerações e o papel que a família exerce na inserção da criança frente à cultura. Portanto, a singularidade de cada paciente pode ser compreendida sob dois prismas: tanto no que se refere às particularidades da família em questão e da relação que se estabelece entre esta e a criança; como também a família e sua criança retratam um exemplo único da condição humana ${ }^{(14)}$.

No caso de M. acolher as questões que se apresentavam como, por exemplo, se o filho seria normal, a vergonha de frequentar a sinagoga por conta dos comportamentos de M., a posição da mãe como intérprete exclusiva dele, foi fundamental para que a inserção de M. em seu ambiente familiar se constituísse. Em nosso entender, o avanço no desenvolvimento de M. estava intimamente relacionado com o fato de o espaço terapêutico ter se constituído como um lugar para favorecer o acontecer humano e, portanto, facilitador do desenvolvimento e da evolução do paciente ${ }^{(10,11)}$.

No que se refere a este estudo, o próprio conceito de clínica voltada à criança já inclui naturalmente os cuidados com o ambiente como uma extensão dos cuidados ao nosso paciente $^{(10,11)}$. Cabe relembrar aqui que o efeito cumulativo de experiências gratificantes e de uma atmosfera amistosa em torno da criança proporciona a construção de sua confiança nas pessoas do mundo externo e de um sentimento geral de segurança. Pode ocorrer, então, o fortalecimento das fundações de seu desenvolvimento emocional, promovendo a integração corpo e mente, dando à criança a sensação de unidade ${ }^{(15)}$.

\section{COMENTÁRIOS FINAIS}

O processo terapêutico vivido com M. deu margem a reflexões sobre a importância do fonoaudiólogo no atendimento à família e faz presente questionamentos quanto ao nosso papel como terapeutas: como lidar com essa família que chega fragilizada por tantas dúvidas? Como lidar com as incógnitas quanto ao futuro do filho? Muitas vezes, ainda sob o impacto de um diagnóstico assertivo do que esse filho não pode ou não vai realizar, os pais procuram (no fonoaudiólogo) respostas prontas sobre o que fazer ou como fazer, em especial no que se refere ao desenvolvimento da comunicação.

Diante das angústias e questões que se colocam em nossa clínica, torna-se fundamental acolher essas famílias, consti-

**** Em novembro/2003 M. foi levado a um neurologista que efetuou o diagnóstico de Transtorno Global do Desenvolvimento. 
tuindo o espaço terapêutico de modo que a criança possa ser vista, por seus pais e familiares, como mais do que sinais e sintomas de uma determinada patologia. O fonoaudiólogo tem a possibilidade de ser aquele que acolhe e respeita a historicidade da pessoa que chega para atendimento clínico como foram disponibilizadas as estratégias terapêuticas no caso de $\mathrm{M}$.

Os atendimentos à família foram direcionados para assinalar os avanços que podiam ser observados na relação de $\mathbf{M}$. com a família, principalmente, no que se referia aos aspectos comunicativos e de interação social. Estes demonstravam, nitidamente, que a linguagem oral passara a ser utilizada como meio de comunicação efetivo entre todos os envolvidos.

Quando buscamos na pessoa como foi e é sua constituição e sua relação com o meio em que vive, temos a oportunidade de entender que nosso paciente traz em si uma história, fruto de sua vivência com o outro desde o início da vida. Nesse sentido, o enfoque terapêutico direciona-se para muito além das manifestações clínicas, dos sintomas, de modo que vamos procurar propiciar um ambiente físico e emocional capaz de promover experiências constitutivas que respeitem a singularidade de cada paciente.

Neste sentido, o fonoaudiólogo pode assumir o papel de mediador entre a criança e a família, em uma posição diferente: não como alguém que detém a receita ou a fórmula do que fazer com a criança com necessidade especial, mas, ao contrário, como parte de um ambiente humano onde se cria a oportunidade de um devir. Ao adotarmos essa postura de reflexão e constituição, temos a oportunidade de respaldar nossa prática nas vivências singulares de cada paciente.

Encerramos este trabalho assinalando que acolher a família e proporcionar o respeito à singularidade do paciente, seus familiares e seu núcleo social favorece mudanças na constituição de suas relações interpessoais, e essas mudanças promovem o desenvolvimento da criança e, consequentemente, modificam sua relação com o outro.

\begin{abstract}
The aim of this study was to reflect about and discuss the role of a speech-language pathologist with the family of a child with Pervasive Development Disorder. This case study reported the case of a child with Pervasive Development Disorder that attended speech-language therapy from July/2002 to November/2004. The excerpts of clinical material depict the course of the patient's history, emphasizing the significant moments that generated development of the therapeutical process related to oral communication and social interaction within his familiar setting. Clinical strategies focused a favorable physical and emotional environment, promoting constitutive experiences that respect the singularity of each patient, considering the realities of the family and the community it is part of. Therefore, in our understanding, speech-language therapy can be directed towards the creation of situations that promote the process [of each patient] of daily life inclusion, with the respect that all people deserve.
\end{abstract}

Keywords: Child development disorders, pervasive; Case studies; Speech therapy; Therapeutical approaches; Family; Family relations

\section{REFERÊNCIAS}

1. American Psychiatry Association. DSM-IV: Manual diagnóstico e estatístico de transtornos mentais. 4a ed. Porto Alegre: Artes Médicas; 1995.

2. Braga MR, Ávila LA. Detecção dos transtornos invasivos na criança: perspectiva das mães. Rev Latinoam Enferm. 2004;12(6):884-9.

3. Fernandes FDM, Teles P. Linguagem nos transtornos do espectro autístico. Rev Soc Bras Fonoaudiol. 2005;10(4):207-10.

4. Silva RA, Lopes-Herrera AS, De Vitto LPM. Distúrbio de linguagem como parte de um transtorno global do desenvolvimento: descrição de um processo terapêutico fonoaudiológico. Rev Soc Bras Fonoaudiol. 2007;12(4):322-8.

5. Fernandes FDM. Terapia de linguagem em crianças com transtornos do espectro autístico. In: Ferreira LP, Befi-Lopes DM, Limongi SCO, organizadores. Tratado de fonoaudiologia. São Paulo: Roca; 2005. p. 941-53.

6. Cardoso C. Funções comunicativas em diferentes situações com crianças do espectro autístico. Rev Soc Bras Fonoaudiol. 2006;11(1):22-7.

7. Sousa-Morato PF, Fernandes FDM. Adaptação sócio-comunicativa no espectro autístico: dados obtidos com pais e terapeutas. Rev Soc Bras Fonoaudiol. 2009;14(2):225-33.
8. Ieto V, Cunha MC. Queixa, demanda e desejo na clínica fonoaudiológica: um estudo de caso clínico. Rev Soc Bras Fonoaudiol. 2007;12(4):329-34.

9. Arantes L. A clínica psicanalítica e a fonoaudiológica com crianças que não falam. Distúrb Comun. 2003;15(1):59-69.

10. Tahan LC, Maia SM. A função terapêutica em Fonoaudiologia. Distúrb Comun. 2005;17(1):115-21.

11. Gertel MCR. O papel do fonoaudiólogo na rede de relações sociais de uma criança com transtorno global do desenvolvimento: estudo de caso [dissertação]. São Paulo: Pontifícia Universidade Católica de São Paulo; 2008.

12. Winnicott DW. O ambiente e os processos de maturação: estudos sobre a teoria do desenvolvimento emocional. Porto Alegre: Artes Médicas; 1983.

13. Winnicott DW. Os bebês e suas mães. 2a ed. São Paulo: Martins Fontes; 1999.

14. Safra G. A pó-ética na clínica contemporânea. 2a ed. Aparecida: Idéias e Letras; 2004.

15. Winnicott DW. Da pediatria à psicanálise: obras escolhidas. Rio de Janeiro: Imago; 2000. A observação de bebês numa situação padronizada (1941). p. 112-33. 